\title{
(RE) PENSANDO A EDUCAÇÃO INFANTIL: UMA PROPOSTA PEDAGÓGICA VALORIZANDO AS CULTURAS DA INFÂNCIA ATRAVÉS DO BRINCAR
}

Nathalia Franco Alves, Jéssika Naiara da Silva, Susana Angelin Furlan, Denise Watanabe, Carolline Rodrigues Guedes, José Milton de Lima, Márcia Regina Canhoto de Lima

Cursos de licenciatura em Educação Física e Pedagogia - FCT/UNESP - Presidente Prudente. Agência financiadora: Programa Núcleo de Ensino - Pró-Reitoria de Graduação da UNESP. Email: nathalia_fa@hotmail.com

\section{RESUMO}

O presente trabalho traz os resultados de uma pesquisa realizada na Educação Infantil, tendo como objeto de estudo a ludicidade e as culturas infantis. Partimos do pressuposto de que muitas educadoras priorizam os saberes relacionados à alfabetização linguística e matemática, olvidando elementos importantes para o desenvolvimento das crianças, como a ludicidade. Os objetivos propostos foram: proporcionar brincadeiras diversificadas ampliando os repertórios lúdicos e imaginativos das crianças; ouvi-las para valorizá-las como sujeitos, possuidoras de cultura; além de estreitar o diálogo com as educadoras discutindo a importância do brincar. Para alcançar tais objetivos utilizamos como metodologia a pesquisa-ação, embasados na Sociologia da Infância. Os resultados mostraram avanços no desenvolvimento motor e cognitivo das crianças; a organização e formulação de regras para as brincadeiras, por elas, demonstrou a expansão do repertório lúdico. Através da valorização das particularidades da infância, percebeu-se a melhoria na relação professor-aluno, favorecendo a comunicação e preocupação com o outro.

Palavras-chave: ludicidade; criança; Sociologia da Infância; socialização; imaginação.

\section{INTRODUÇÃO}

O presente artigo "(Re) pensando a Educação Infantil: uma proposta pedagógica valorizando as culturas da infância através do brincar" expõe o resultado de um projeto de extensão realizado com 230 alunos, divididos em duas instituições de Educação Infantil I e II, com idades entre três e cinco anos, no município de Álvares Machado, São Paulo. A pesquisa é realizada em parceria com a prefeitura municipal da cidade em que a instituição escolar está localizada e o Centro de Estudos e Pesquisa em Educação, Ludicidade, Infância e Juventude (CEPELIJ) pertencente e financiado pela Faculdade de Ciências e Tecnologia, UNESP - Campus Presidente Prudente.

Assumimos como suporte teórico a Sociologia da Infância que percebe a criança como sujeito ativo, capaz, competente em suas ações, atividades e protagonista. No entanto, compreendemos que a infância como uma "categoria social" não foi sempre vista dessa forma, tal visão se deu através do tempo, e foi construída historicamente. Alguns estudiosos datam seu surgimento na Idade Medieval. 
Crianças existiram sempre, desde o primeiro ser humano, e a infância como construção social - a propósito da qual se construiu um conjunto de representações sociais e de crenças e para a qual se estruturaram dispositivos de socialização e controlo que a instituíram como categoria social própria - existe desde os séculos XVII e XVIII. (SARMENTO, 1997, p.13).

Segundo Corsaro (2011), foi Ariès quem contribuiu para que o "sentimento de infância" surgisse. Seus estudos chamaram a atenção dos historiadores da época, suscitando um olhar para essa que, como "categoria" ainda não era reconhecida, mas que necessitava de atenção e valor. Com o passar do tempo, com as mudanças econômicas, históricas e sociais ocorreu uma institucionalização infantil. Houve um crescente interesse por espaços que pudesse garantir cuidado e proteção às crianças. Contudo, os estudos sobre as crianças restringiam-se apenas ao ponto de vista de familiares e/ou das Instituições destinadas a elas. As falas infantis não eram consideradas e os adultos, muitas vezes falavam da criança e até pela criança.

A Sociologia da Infância tem sido uma das áreas mais significativas de estudos na atualidade que tem buscado superar tais visões adultocêntricas. Ela considera as crianças como atores sociais criativos, protagonistas que influenciam e são influenciados pelo meio em que vivem que produzem cultura própria, enquanto se apropriam, reproduzem e reinterpretam a cultura adulta; e a infância uma construção histórica e social que sofre influências do meio contextual ao qual está inserida. Ela compreende as diferenças entre as crianças e as infâncias, seus desejos, especificidades, formas de ver e viver no mundo.

Corsaro (2011), pesquisador etnográfico, realizou pesquisas em diversas escolas italianas e americanas de Educação Infantil e trouxe importantes contribuições para a área da Sociologia da Infância, sendo ele um dos principais autores dessa vertente. Ele buscou diminuir a distancia que existia entre a criança e o adulto, evidenciando a importância de se escutar as falas infantis, tornando-se, justamente por isso, na visão das crianças pesquisadas, um "adulto atípico".

Nesse sentido, compreender tal concepção sobre criança e infância é necessário para que se possa valorizar e enriquecer as culturas infantis, que possibilitam e geram o desenvolvimento integral do sujeito, em especial, destacaremos as atividades lúdicas, brincadeiras, como essenciais para o processo de formação humano, socialização e compreensão do mundo.

Entretanto, apesar do crescente número de produções científicas e textos existentes na atualidade, que buscam evidenciar a ludicidade como indispensável para a criança, ainda existem professoras e instituições de Educação Infantil que não compreendem a importância de tais 
atividades para a aprendizagem e o desenvolvimento global infantil. Muitas educadoras, ainda fomentam em suas salas de aula somente os saberes relacionados à alfabetização linguística e matemática exclusiva, esquecendo-se de outros elementos importantes, destaque para o lúdico, o artístico, o interativo e o emocional. As relações, por vezes, centradas apenas nas falas dos adultos, olvidam a participação e falas infantis.

Diante disso, defendemos que as instituições educacionais necessitam reconhecer e concretizar o seu papel no processo de ensino-aprendizagem e formação das crianças, dialogando com a produção legal e científica atual, numa relação entre teoria e prática. Reconhecendo tal realidade, constituem-se como objetivos do estudo introduzir e expandir a cultura lúdica dentro das instituições parceiras, ampliar o repertório de brincadeiras das educadoras e, principalmente, das crianças, na expectativa de que elas as resignifiquem e reproduzam juntamente com os pares, professoras, pais e até mesmo sozinhas.

\section{DESENVOLVIMENTO}

Sarmento (2004) enfatiza que as crianças possuem formas próprias de se expressar e de se relacionar, que podem ser representadas através dos quatro Eixos Estruturadores das Culturas Infantis, que são: interactividade, ludicidade, fantasia do real e reiteração. A ludicidade e a fantasia do real possuem estreita relação, embora todos os quatro eixos relacionam-se entre si e possuem particularidades.

A ludicidade permite a criança desenvolver sua criatividade, imaginação, habilidades motoras, cognitivas, fomentar as relações sociais, afetivas, emocionais, entre outras. É uma das principais atividades realizadas pelas crianças, embora não seja exclusividade delas, mas uma ação tipicamente humana. Para os adultos brincar não é considerado primordial. Muitas vezes é visto como específico das crianças, ou como uma distração a ser realizada no tempo livre, uma atividade secundária ligada ao lazer cujo intuito maior é a diversão. Brincar é uma especificidade humana que não se restringe somente às crianças, mas pode ser realizada por jovens, idosos e adultos, independente do sexo, da idade, da condição financeira. O que difere é a importância e o tempo destinado para essa atividade, que variam entre adultos e crianças.

Para Sarmento (2004), "[...] Contrariamente aos adultos, entre brincar e fazer coisas sérias não há distinção, sendo o brincar muito do que as crianças fazem de mais serio". Para os adultos, por exemplo, brincar é algo secundário, já que existem outros afazeres mais importantes, como trabalhar, estudar, cuidar da casa, fazer compras, etc. A brincadeira é uma forma da criança de se 
relacionar com seus pares, com os adultos, com o mundo à sua volta, que permite a ela conhecer a si mesma e aos outros, permite imaginar, criar, transformar, aprender. Brincar possibilita a criança pensar, ter experiências diversificadas, aprender, ensinar, interagir com o outro, se socializar, lidar com regras, desenvolver sentimentos como os de perder e ganhar, de competir individualmente ou em equipe, criar ou quebrar regras, estratégias, descobrir formas, etc.

Para Lima (2008):

Quando brinca ou joga, a criança transforma objetos, animais, pessoas, lugares, coordena diferentes experiências, através da memória e da imaginação. O momento de brincar pode ser visto como um laboratório, um espaço de experimentação, no qual a criança pode ensaiar, errar, sem a pressão do mundo adulto. A criança, por meio da linguagem simbólica, utiliza-se de objetos, insere-se no mundo da cultura, constrói o pensamento, lida com seus sentimentos e amplia suas relações sociais. (BRASIL, 1998b, p. 10-11 apud LIMA 2008 p. 14).

A fantasia do real possui estreita relação com a ludicidade e permite que a criança invente, crie, recrie, construa, interprete pessoas, cenas vistas ou vividas, situações rotineiras, difíceis, tristes, ou complexas para sua compreensão. Através dela a criança pode transpor objetos, situações, ficar mais perto de seu personagem preferido, do herói televisivo que, durante a brincadeira se faz presente, através de um boneco, ou objeto, que pode assumir diversas formas e ter significados distintos, conforme a imaginação e criatividade infantil.

A interactividade é a capacidade que a criança tem em relacionar-se com seus pares, com o outro, com as pessoas à sua volta. É o momento de troca de experiências e de descobrimentos, de dividir atividades, brincadeiras e brinquedos. "É um conjunto de actividades ou rotinas, artefactos, valores e preocupações que as crianças produzem e partilham na interacção com seus pares" (CORSARO, 1997 p. 114).

A reiteração é um tempo que pode ser recursivo, que permite à criança recomeçar sua brincadeira do mesmo lugar que parou, seja passado, presente ou futuro, sem que perca sua função e podendo ser recomeçado de novo e de novo, todas as vezes que se repete o "era uma vez"...

Por fim, a partir da discussão realizada acima e por meio das intervenções no ambiente educacional a pesquisa possibilitou ampliar o rol de atividades lúdicas e imaginativas dos alunos e das professoras do contexto analisado; contribuiu com a formação continuada das educadoras e permitiu o aprofundamento teórico e prático dos alunos dos cursos de licenciatura em Educação 
Física e Pedagogia, permitindo a estreita relação entre os estudos teóricos e a vivência prática, que possibilita a reflexão, a ação e mudança da realidade pesquisada.

\section{METODOLOGIA}

A presente pesquisa está amparada no Protocolo do Comitê de Ética em Pesquisa (CEP): Processo no 71/2009, da FCT/UNESP de Presidente Prudente.

A metodologia utilizada na pesquisa de extensão tem caráter qualitativo e utiliza-se da pesquisa-ação, na qual busca refletir e aprimorar o assunto tratado, e através do que foi aprendido é aplicado na instituição buscando modificar a realidade encontrada. As intervenções ocorrem uma vez por semana, durante aproximadamente 50 minutos em cada turma. São utilizadas fantasias, estórias, jogos, brinquedos, atividades cooperativas, tudo que possa influenciar e estimular a imaginação infantil e possa aprimorar o repertorio lúdico das crianças e das educadoras. É utilizado um diário de campo onde os resultados mais significativos são coletados e inseridos, assim como relatos, conversas, observações, etc. Utilizamos recursos tecnológicos para obter imagens, gravações, assim como utilizamos questionários com educadoras, funcionários e familiares.

São realizadas reuniões semanais no CEPELIJ e estudos quinzenais com os pesquisadores. Fazem parte desse grupo, professores doutores, mestrandos e graduandos, dos cursos de licenciatura em Educação Física e Pedagogia. São discutidos textos, artigos, livros, que abordam o referencial teórico da Sociologia da Infância e que permitem um maior entendimento do que é a infância e o ser criança. Nesse espaço também são elaborados os planos de aulas e debates referentes ao desenvolvimento do trabalho realizado nas instituições pesquisadas.

\section{RESULTADOS}

A partir das considerações teóricas acima, foi necessário direcionar o olhar para questões que são essenciais na busca da melhoria do brincar. Inicialmente, tendo o tempo e o espaço destinado ao brincar como foco na pesquisa verificou-se que tais atividades lúdicas eram na maioria das vezes desenvolvidas dentro da sala de aula, com o intuito de trabalhar e/ou ensinar algum conceito linguístico ou matemático específico. Ao final dessas atividades direcionadas dentro da sala de aula e com um objetivo pedagógico pré-determinado, percebíamos a insatisfação das crianças no momento em que questionavam as professoras da seguinte maneira: "Depois disso vamos brincar?", ou ainda, quando os pesquisadores questionavam se já haviam 
brincado naquele dia e elas, mesmo após a atividade proposta pela professora, respondiam que "Não". Esta realidade demonstra que as brincadeiras trabalhadas em sala de aula não tinha caráter lúdico para os participantes, isto é, as atividades possuíam uma finalidade prédeterminada - ensinar elementos presentes em outras áreas do conhecimento.

Ficou perceptível na instituição que possuía uma brinquedoteca com amplo espaço e diversos objetos e brinquedos o pouco usufruto do espaço destinado especificamente a ludicidade. Com efeito, o mesmo acontecia com a instituição que possuía uma quadra poliesportiva coberta, poucas vezes encontrávamos turmas utilizando determinado espaço. Os exemplos descritos confirmam a proposição que o tempo e espaço destinado ao brincar tem sido secundarizado em detrimento de outras atividades, uma vez que as observações revelaram que as crianças brincam somente em momentos esporádicos e quando acabam as suas respectivas tarefas. Tais episódios demonstram de maneira clara que a formulação dos tempos e espaços destinados ao brincar é uma efetivação adultocêntrica, uma vez que preconiza atividades que estão no planejamento institucional e não as especificidades atuais da criança.

Buscou-se por meio das intervenções, ampliar o tempo destinado as atividades lúdicas e ainda, criar possibilidades de utilização dos diferentes espaços e ambientes. Diante disso, as turmas passaram a ter mais tempo de atividades lúdicas realizadas no pátio, quadra, brinquedoteca e até mesmo na sala de vídeo. O tempo do intervalo de uma das instituições foi ampliado para mais dez minutos, tal fato se deu, visto que a direção e coordenação, por meio de diálogos com a equipe da pesquisa e observações realizadas durante as brincadeiras, notaram a necessidade e a importância que a brincadeira tem para o desenvolvimento integral das crianças e maior socialização entre elas. Além dessas práticas redirecionadas, houve-se também avanço na maneira como os brinquedos e objetos eram possibilitados para as crianças, ou seja, eles passaram a ser colocados no pátio ao alcance das crianças nos momentos de intervalo.

Por fim, a partir da ampliação do tempo destinado as atividades lúdicas nos diferentes espaços da instituição e com a possibilidade de alcance dos brinquedos, notou-se que as crianças demonstraram avanços qualitativos na comunicação durante as rodas de conversa no início e fim das intervenções; estão mais autônomas, ou seja, elas próprias organizam as brincadeiras nos momentos livres, como por exemplo, nos recreios e horário da entrada e saída, passaram a definir coletivamente as regras que serão aplicadas em cada brincadeira e ainda criaram novas possibilidades de repertórios lúdicos, criando novas brincadeiras a partir de outras já conhecidas. A interação entre as crianças foi mais significativa em relação aos gêneros. 
Quanto às professoras, foi aplicado um questionário com o objetivo de avaliar e acompanhar o desenvolvimento da pesquisa e das intervenções. Uma das questões perguntava se o projeto tinha possibilitado modificações na prática pedagógica e se sim, quais. Todas as entrevistadas argumentaram que o projeto modificou a sua visão, auxiliando na melhora da sua prática:

- "Para a minha prática pedagógica mudei as minhas concepções sobre as brincadeiras e passei a dar grande importância a estes momentos".

- "Sim, o brincar ajuda a desenvolver em todos os aspectos a criança, emocional, cognitivos e coordenação".

-"Sim, anteriormente era muito focada dentro da sala de aula, preocupada com o pedagógico e hoje vejo o brincar com melhores olhos".

-"Sim, o projeto desenvolve o aprendizado através das brincadeiras, contos e outras atividades, facilitando o desenvolvimento do aluno...".

As educadoras, em sua maior parte, participam ativamente das atividades, interagindo e auxiliando numa maior ligação professor-aluno. O que proporciona uma amplitude em seus conhecimentos e repertórios de brincadeiras, que posteriormente, são reproduzidas em outras ocasiões. Em depoimentos, algumas disseram que as crianças passaram a ser mais comunicativas e presentes nas atividades em sala. Nota-se uma maior parceria entre elas. Algo observado foi um aluno de seis anos, antes muito violento e agressivo, agora repartindo seus brinquedos com os colegas de classe, além de estar mais envolto. Ações como essas deixam claro que a cumplicidade das crianças vem sendo aumentados, além de progredirem em seus desenvolvimentos motor e cognitivo, percebe-se que existe uma maior preocupação em como agir com o outro. Em conversas realizadas com as mesmas, observamos que a sua fantasia sofreu uma transformação, eles se encantam com as historias contadas e buscam reproduzi-las entre si.

\section{DISCUSSÃO DOS RESULTADOS}

De acordo com Brown (in MOYLES, 2006), os tempos e espaços normalmente são planejados segundo o ritmo do adulto, enquanto isso são as crianças que precisam se adequar a essa estrutura rotineira, mesmo sendo ela um sujeito de direitos, que, além do direito à brincadeira, tem o direito de criar, inventar, tomar decisões etc., construindo assim sua identidade e individualidade dentro de um tempo e de um espaço próprio e necessário para garantir essa construção. 
Anning (2006) argumenta através de evidências proporcionadas por diversas pesquisas que é preciso buscar uma alternativa radical para o currículo da educação infantil. Para a autora, esse currículo alternativo teria por objetivo capacitar a criança com instrumentos de pensamento, capacitando-a a explorar um leque completo de ideias, experiências, sentimentos e relacionamentos através do brincar.

\section{CONCLUSÕES}

O contexto da Educação Infantil é um espaço privilegiado para que as crianças se desenvolvam amplamente em todos os aspectos, cognitivos, sociais e motores. No entanto, para isso, é necessário que as crianças sejam vistas e repeitadas como atores sociais, com particularidades, necessidades e cultura própria. Nessa direção, vale ressaltar ainda, que é responsabilidade dos adultos, educadores e das Instituições de Educação Infantil assegurar os direitos civis e humanos das crianças.

Necessita-se ainda, que o conceito de criança e infância, assim como a importância da brincadeira e da imaginação esteja esclarecido e compreendido por todos os envolvidos no contexto da Educação Infantil. E que por meio desde entendimento tal espaço seja um lugar de ampliar as vivências de forma significativa para as crianças e não se torne um lugar de alfabetização precoce e antecipação do Ensino Fundamental.

Dessa maneira, na busca de cumprir com as indagações teóricas e assim alcançar os objetivos propostos inicialmente, concluí-se que través das intervenções desenvolvidas foi possível expandir o repertório de atividades lúdicas das crianças e das educadoras, conscientizar a direção, coordenação, funcionários e educadoras da importância das atividades propostas pelo projeto.

Espera-se que a pesquisa apresentada possa contribuir para que, por meio das brincadeiras e da esfera lúdico imaginativa, as crianças obtenham a oportunidade de desenvolver a sociabilidade, de desfrutar das culturas de pares, ter sua imaginação estimulada e ainda ter a vivencia das culturas da infância respeitadas.

\section{REFERÊNCIAS}

ANNING, A. O brincar e o currículo oficial. De volta ao básico: uma visão alternativa. In. MOYLES, J. R. A excelência do brincar. Porto Alegre: Artmed, 2006. 248p.

CORSARO, W. Sociologia da Infância. Porto Alegre: Artmed, 2011. 
LIMA, J. M. O jogo como recurso pedagógico no contexto educacional. São Paulo: Cultura acadêmica: 2008.157p.

SARMENTO, M. J.. As culturas da infância nas encruzilhadas da 2a modernidade. Braga: Instituto de Estudos da Criança, Universidade do Minho, 2004. (texto digitado).

Imaginário e culturas da infância. Cadernos de Educação, Pelotas, v. 12, n. 21, p. 5169, 2004.

SARMENTO, M., \& Pinto, M. (1997). As Crianças e a Infância: Definindo Conceitos, Delimitando o Campo. In Sarmento, M., Pinto, M., (1997). As Crianças: Contextos e Identidade. Braga: IESC-UM. 